\title{
Circulating microRNAs as prognostic therapy biomarkers in head and neck cancer patients
}

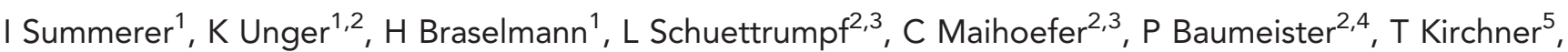
M Niyazi ${ }^{2,3}$, E Sage $^{6}, \mathrm{H}$ M Specht ${ }^{6}, \mathrm{G} \mathrm{Multhoff}^{6,7}, \mathrm{~S} \mathrm{Moertl}^{8}, \mathrm{C}$ Belka $^{2,3}$ and H Zitzelsberger ${ }^{\star, 1,2}$

${ }^{1}$ Research Unit Radiation Cytogenetics, Helmholtz Center Munich, Ingolstaedter Landstrasse 1, 85764 Neuherberg, Germany; ${ }^{2}$ Clinical Cooperation Group 'Personalized Radiotherapy of Head and Neck Cancer', Helmholtz Center Munich, Ingolstaedter Landstrasse 1, 85764 Neuherberg, Germany; ${ }^{3}$ Department of Radiation Oncology, Ludwig-Maximilians-Universitaet Muenchen, Marchioninistrasse 15, 81377 Munich, Germany; ${ }^{4}$ Department of Otorhinolaryngology, Head and Neck Surgery, LudwigMaximilians-Universitaet Muenchen, Marchioninistrasse 15, 81377 Munich, Germany; Institute of Pathology, Ludwig-MaximiliansUniversitaet Muenchen, Thalkirchner Strasse 36, 80337 Munich, Germany; ${ }^{6}$ Department of Radiation Oncology, Technische Universitaet Muenchen, Ismaninger Strasse 22, 81675 Munich, Germany; 'Clinical Cooperation Group 'Innate Immunity', Helmholtz Center Munich, Ingolstaedter Landstrasse 1, 85764 Neuherberg, Germany and Institute of Radiation Biology, Helmholtz Center Munich, Ingolstaedter Landstrasse 1, 85764 Neuherberg, Germany
\end{abstract}

Background: The prediction of therapy response in head and neck squamous cell cancer (HNSCC) requires biomarkers, which are also a prerequisite for personalised therapy concepts. The current study aimed to identify therapy-responsive microRNAs (miRNAs) in the circulation that can serve as minimally invasive prognostic markers for HNSCC patients undergoing radiotherapy.

Methods: We screened plasma miRNAs in a discovery cohort of HNSCC patients before therapy and after treatment. We further compared the plasma miRNAs of the patients to age- and sex-matched healthy controls. All miRNAs identified as biomarker candidates were then confirmed in an independent validation cohort of HNSCC patients and tested for correlation with the clinical outcome.

Results: We identified a signature of eight plasma miRNAs that differentiated significantly $(P=0.003)$ between HNSCC patients and healthy donors. MiR-186-5p demonstrated the highest sensitivity and specificity to classify HNSCC patients and healthy individuals. All therapy-responsive and patient-specific miRNAs in plasma were also detectable in tumour tissues derived from the same patients. High expression of miR-142-3p, miR-186-5p, miR-195-5p, miR-374b-5p and miR-574-3p in the plasma correlated with worse prognosis.

Conclusions: Circulating miR-142-3p, miR-186-5p, miR-195-5p, miR-374b-5p and miR-574-3p represent the most promising markers for prognosis and therapy monitoring in the plasma of HNSCC patients. We found strong evidence that the circulating therapy-responsive miRNAs are tumour related and were able to validate them in an independent cohort of HNSCC patients.

Squamous cell carcinomas represent the most common malignancies of the head and neck region. About two-thirds of patients with head and neck squamous cell carcinoma (HNSCC) exhibit advanced stage disease, usually involving regional lymph nodes (Argiris et al, 2008). Advanced HNSCC have often a poor prognosis despite intensive local treatment due to tumour recurrences and distant metastases. About $50-60 \%$ of patients with advanced disease develop local or regional recurrences after treatment (Hoffmann, 2012).

Known risk factors for the development of HNSCC are tobacco use and alcohol consumption (Blot et al, 1988; Tuyns et al, 1988), as well as human papillomavirus (HPV) infection, mainly type 16 ,

*Correspondence: Professor H Zitzelsberger; E-mail: zitzelsberger@helmholtz-muenchen.de

Received 9 December 2014; revised 19 February 2015; accepted 27 February 2015; published online 9 June 2015

(c) 2015 Cancer Research UK. All rights reserved 0007-0920/15 
which particularly increases the risk for tonsillar and oropharyngeal cancers (D'souza et al, 2007). Human papillomaviruspositive HNSCC tumours have a favourable prognosis (Licitra et al, 2006; Bledsoe et al, 2013) and show a better therapy response (Argiris et al, 2008). Thus, HPV status represents a valuable predictive biomarker that should be taken into consideration for treatment planning to prevent excessive therapy.

To date no biomarker for therapy monitoring or patient surveillance is established. Predictive biomarkers in the peripheral blood, such as the newly identified marker HSP70 in HNSCC patients (Gehrmann et al, 2014), provide a minimally invasive way to predict therapy outcome. Recently, it was shown that microRNAs (miRNAs) in plasma samples exhibit high stability and are resistant to RNase activity (Mitchell et al, 2008). This stability combined with the good accessibility make circulating miRNAs attractive biomarker candidates. MiRNAs represent a class of promising biomarkers in cancer research since they are highly specific and are associated with pathoclinical parameters of the disease (Sethi et al, 2013). They can have protective or carcinogenic effects by post-transcriptional regulation of either tumour suppressor genes (Zheng et al, 2011) or oncogenes (Nohata et al, 2011). Since miRNAs are part of the cellular stress response they bear a high potential for diagnostic and prognostic use in cancer patients (Li et al, 2009).

The aim of the present study was to evaluate blood plasma miRNAs as minimally invasive biomarkers for radiotherapy monitoring and prognosis. For this purpose, we used a cohort of HNSCC patients with locally advanced and unresectable tumours undergoing radiochemotherapy or radiotherapy alone, which is the common treatment for these cases (Adelstein et al, 2003). We previously analysed the therapy effect on the plasma miRNAs by comparing the miRNA profiles in plasma of HNSCC patients before therapy and after the completion of the first two fractions of therapeutic irradiation (Summerer et al, 2013). MiRNAs showing changed levels were tested in the present study to determine their prognostic value and their potential for predicting the individual tumour response to radio(chemo)therapy. For this purpose, we tested the expression levels of the miRNAs for their correlation with locoregional tumour control (LRC), progression-free survival (PFS) and overall survival (OS). To check for a possible tumour origin of the therapy-regulated plasma miRNAs, we compared miRNA levels in plasma samples from HNSCC patients prior to treatment with an age- and sex-matched group of healthy donors. MiRNAs that were identified as patient-specific markers or as therapy-responsive miRNAs were validated in an independent HNSCC patient cohort. To further support the hypothesis that the detected alterations in plasma miRNAs are tumour related, we analysed tumour biopsies from the same patient cohorts.

\section{MATERIALS AND METHODS}

\section{Patients and samples}

Discovery cohort. The discovery cohort comprising 18 HNSCC patients treated with radio(chemo)therapy was described earlier in the study by Summerer et al (2013). All patients were treated with local X-ray-irradiation using a linear accelerator (6 MV, Siemens Mevatron M, Siemens Medical Solutions, Malvern, PA, USA or ELEKTA Synergy, ELEKTA, Stockholm, Sweden). After a planning (PET-)CT scan, 70 Gy of radiation was applied to the macroscopic tumour and involved lymph nodes in daily dose fractions of $2 \mathrm{~Gy}$, 5 days per week. The adjuvant lymphatics were irradiated with up to $50 \mathrm{~Gy}$ and the high-risk lymphatics (adjacent to the involved lymph node levels) with up to $60 \mathrm{~Gy}$. Seventeen out of 18 patients received concurrent chemotherapy (13 patients received 5fluorouracil (5-FU) plus mitomycin C (MMC), 3 patients MMC and 1 patient cisplatin weekly). None of the patients underwent surgical treatment. 5-fluorouracil treatment was usually applied on each of the first 5 days of therapeutic irradiation, whereas MMC was applied only on day 5 and day 36 during radiotherapy. Patient characteristics, therapy conditions and pathoclinical parameters are listed in Table 1. After obtaining informed consent, $15 \mathrm{ml}$ EDTA peripheral blood was collected prior to therapy and after the second fraction of therapeutic irradiation to detect therapyresponsive plasma miRNAs. About $10 \mu \mathrm{m}$ formalin-fixed paraffin-embedded (FFPE) slides from tumour biopsies of 10 out of the 18 patients, which were retrieved prior to therapy, were provided by the Institute of Pathology at the Ludwig-MaximiliansUniversity Munich.

Validation cohort. For validation of candidate biomarker miRNAs a set of 11 HNSCC patients treated with radiotherapy was selected. Radiotherapy was applied in the same manner as in the discovery cohort. None of the patients underwent surgical treatment. Eight patients received concurrent chemotherapy (five patients cisplatin, two patients MMC and one patient 5-FU plus MMC). For patient 1, cisplatin was applied once per week. For patients 6, 8, 10 and 11 cisplatin was applied in the first and the fifth week of radiotherapy for a period of 5 days in each week. 5-fluorouracil treatment was applied on each of the first 5 days of therapeutic irradiation, whereas MMC was applied only on day 5 and day 36 during radiotherapy. Characteristics, therapy conditions and pathoclinical parameters of the validation cohort are listed in Table 2. Blood samples were obtained prior to therapy and after the second fraction of therapeutic irradiation in the same manner as in the discovery cohort. About $10 \mu \mathrm{m}$ FFPE slides from tumour biopsies of 4 out of the 11 patients retrieved prior to therapy were provided by the Institute of Pathology at the LudwigMaximilians-University Munich.

The study was approved by the ethics committee of the University of Munich (Germany).

Healthy donors. Twelve age- and sex-matched controls were selected to elucidate the origin of the plasma miRNA signatures in HNSCC patients. The cohort comprised nine male and three female individuals with a median age of 57.2 years (age range 37-68 years). After obtaining informed consent, EDTA-samples of $8 \mathrm{ml}$ of peripheral blood were collected from healthy volunteers.

RNA extraction from plasma and FFPE tissue. Total RNA was extracted from plasma according to the study by Summerer et al (2013).

Formalin-fixed paraffin-embedded-slides were deparaffinised in xylene, washed in isopropanol and rehydrated in ethanol (100 and $70 \%)$. After microdissection for removal of normal tissue, RNA was isolated using the RNeasy FFPE Kit (Qiagen, Venlo, Netherlands) following the manufacturer's protocol. RNA was eluted in RNAse-free water (Life Technologies, Carlsbad, CA, USA) with a final volume of $25 \mu \mathrm{l}$. Quality assessment using a Nanodrop ND1000 (Thermo Scientific, Waltham, MA, USA) exhibited OD 260/ 280 ratios in the range of 1.7 to 2.0 .

MicroRNA profiling. MicroRNA profiling in blood plasma samples generated with TaqMan Array Human MicroRNA A Cards v2.0 (Applied Biosystems, Waltham, MA, USA) was previously specified in the study by Summerer et al (2013).

Individual miRNA quantification by $\mathrm{qRT}$-PCR. Quantification of individual miRNAs via qRT-PCR was performed as described before (Summerer et al, 2013). MiRNAs were considered deregulated when showing a fold change (FC) of $0.75 \leqslant F C \geqslant 1.33$ since single qRT-PCR assays usually show smaller FCs than arrays.

Locoregional control and survival analysis. The locoregional control of the tumour was defined as the time from the date of 
Table 1. Characteristics and clinical parameters of patients in the discovery set

\begin{tabular}{|c|c|c|c|c|c|c|c|c|c|c|c|}
\hline Patient & Gender & $\begin{array}{c}\text { Age } \\
\text { (years) }^{a}\end{array}$ & $\begin{array}{l}\text { Tumour } \\
\text { site }\end{array}$ & Histology & $\mathrm{TNM}^{\mathrm{b}}$ & HPV & $\begin{array}{c}\text { Cumulative } \\
\text { dose (Gy) }\end{array}$ & $\begin{array}{c}\text { Concomitant } \\
\text { therapy }\end{array}$ & $\begin{array}{c}\text { Acute } \\
\text { toxicity }\end{array}$ & $\begin{array}{l}\text { Progress/ } \\
\text { death } \\
(\text { event }=1)\end{array}$ & $\begin{array}{c}\text { Locoregional } \\
\text { control }^{\mathrm{d}} / \text { overall } \\
\text { survival }^{\mathrm{e}} \text { (weeks) }\end{array}$ \\
\hline 1 & $\mathrm{M}$ & 80 & Larynx & SCC & $\begin{array}{l}\text { T3 } \\
\text { N1a } \\
\text { M0 }\end{array}$ & NA & 70 & MMC & Severe & $0 / 0$ & $81.9 / 90.0$ \\
\hline 2 & M & 70 & Oropharynx & $\mathrm{SCC}$ & $\begin{array}{l}\mathrm{T} 2 \\
\mathrm{~N} 2 \mathrm{c} \\
\mathrm{MO}\end{array}$ & NA & 70 & 5-FU/MMC & Severe & $0 / 1$ & $38.3 / 40.9$ \\
\hline 3 & $\mathrm{M}$ & 49 & $\begin{array}{l}\text { Maxillary } \\
\text { sinus }\end{array}$ & SCC & $\begin{array}{l}\mathrm{T} 4 \\
\mathrm{~N} 2 \mathrm{c} \\
\mathrm{M} 0\end{array}$ & - & 70 & 5-FU/MMC & Mild & $1 / 1$ & 15.0/18.9 \\
\hline 4 & $\mathrm{M}$ & 63 & Larynx & SCC & $\begin{array}{l}\mathrm{T} 4 \\
\mathrm{~N} 2 \mathrm{c} \\
\mathrm{M} 1\end{array}$ & + & 60 & Cetuximab & Severe & $0 / 1$ & $48.0 / 52.3$ \\
\hline 5 & $\mathrm{~F}$ & 63 & Oropharynx & $\mathrm{SCC}$ & $\begin{array}{c}\text { T3 N1 } \\
\text { M0 }\end{array}$ & + & 70 & 5-FU/MMC & Severe & $0 / 1$ & $57.1 / 61.1$ \\
\hline 6 & M & 77 & Oropharynx & SCC & $\begin{array}{l}\text { T2 } \\
\text { N2c } \\
\text { MO }\end{array}$ & + & 70 & 5-FU/MMC & Mild & $0 / 0$ & $144.1 / 147.1$ \\
\hline 7 & $\mathrm{M}$ & 52 & Oral cavity & SCC & $\begin{array}{l}\text { T4 } \\
\text { N2b } \\
\text { M0 }\end{array}$ & + & 70 & 5-FU/MMC & Severe & $1 / 1$ & $16.9 / 39.4$ \\
\hline 8 & $\mathrm{~F}$ & 45 & Nasopharynx & SCC & $\begin{array}{c}\mathrm{T} 2 \mathrm{~b} \\
\mathrm{~N} 1 \mathrm{M} 0\end{array}$ & - & 70 & Cisplatin & Severe & $1 / 0$ & $117.4 / 127.9$ \\
\hline 9 & M & 54 & $\begin{array}{l}\text { Paranasal } \\
\text { sinuses }\end{array}$ & SCC & $\begin{array}{c}\text { T4b } \\
\text { NO MO }\end{array}$ & - & 70 & 5-FU/MMC & Severe & $0 / 0$ & $8.3 / 21.3$ \\
\hline 10 & M & 47 & Hypopharynx & SCC & $\begin{array}{l}\text { T4 } \\
\text { N2c } \\
\text { M0 }\end{array}$ & - & 70 & 5-FU/MMC & Mild & $0 / 0$ & $111.3 / 115.4$ \\
\hline 11 & $\mathrm{~F}$ & 79 & $\begin{array}{l}\text { Oro/ } \\
\text { nasopharynx }\end{array}$ & SCC & $\begin{array}{l}\text { T3 } \\
\text { N2b } \\
\text { M0 }\end{array}$ & - & 70 & 5-FU/MMC & Severe & $0 / 1$ & $6.0 / 13.3$ \\
\hline 12 & $M$ & 50 & Larynx & $\mathrm{SCC}$ & $\begin{array}{l}\mathrm{T} 4 \\
\mathrm{~N} 2 \mathrm{c} \\
\mathrm{MO}\end{array}$ & - & 70 & 5-FU/MMC & Severe & $0 / 0$ & $106.3 / 113.3$ \\
\hline 13 & $M$ & 46 & Larynx & SCC & $\begin{array}{l}\text { T1 } \\
\text { N2c } \\
\text { MO }\end{array}$ & - & 70 & 5-FU/MMC & Mild & $0 / 0$ & $33.7 / 43.6$ \\
\hline 14 & $\mathrm{~F}$ & 78 & Oropharynx & SCC & $\begin{array}{l}\text { T1 } \\
\text { N2b } \\
\text { M0 }\end{array}$ & + & 70 & MMC & NA & $0 / 0$ & $103.3 / 108.9$ \\
\hline 15 & $M$ & 70 & Larynx & SCC & $\begin{array}{l}\text { T3 } \\
\text { N2b } \\
\text { M0 }\end{array}$ & NA & 70 & 5-FU/MMC & Severe & $0 / 0$ & $101.0 / 106.0$ \\
\hline 16 & $M$ & 57 & Oropharynx & SCC & $\begin{array}{c}\text { T3 NO } \\
\text { MO }\end{array}$ & + & 70 & 5-FU/MMC & Mild & $0 / 0$ & $103.3 / 93.0$ \\
\hline 17 & M & 58 & Oral cavity & SCC & $\begin{array}{l}\text { T1 N1 } \\
\text { M0 }\end{array}$ & - & 70 & 5-FU/MMC & Severe & $1 / 1$ & $4.1 / 43.7$ \\
\hline 18 & $M$ & 50 & Oral cavity & SCC & \begin{tabular}{|c|}
$\begin{array}{c}\text { T1 No } \\
\text { M0 }\end{array}$ \\
\end{tabular} & - & 70 & MMC & Severe & $0 / 1$ & $52.1 / 62.7$ \\
\hline \multicolumn{12}{|c|}{ 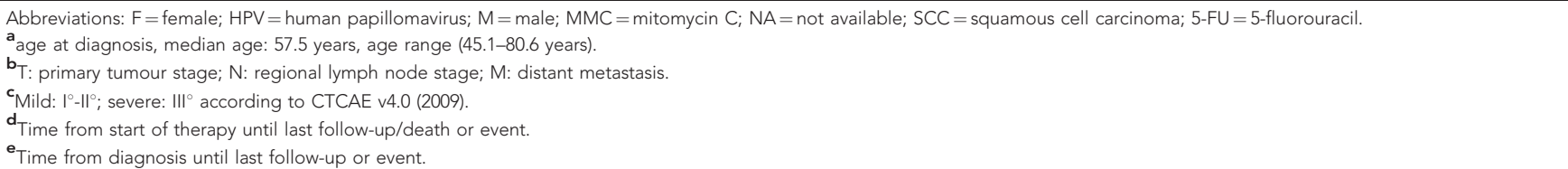 } \\
\hline
\end{tabular}

therapy start until last follow-up/death or event. A progress of the primary tumour or metastases in the locoregional lymphatics were considered as an event, whereas distant metastases were not considered as an event. End of follow-up or tumour-independent death was censored. Locoregional control was assessed by CT scan or sonography. Progression-free survival was determined as the time from the date of therapy start until event (death or progress) or last follow-up (censored). Progress was assessed in accordance with the LRC analysis. Overall survival was defined as the time from diagnosis until event (death) or last follow-up (censored). The correlation analysis of miRNA expression with LRC, PFS and OS was based on the results of the single qRT-PCR assays. Patients were split into two groups, displaying either a $\Delta \mathrm{Ct}$ value $\geq$ median $\Delta \mathrm{Ct}$ or $<$ median $\Delta \mathrm{Ct}$ for the miRNA of interest, referring to low 
Table 2. Characteristics and clinical parameters of patients in the validation set

\begin{tabular}{|c|c|c|c|c|c|c|c|c|c|c|c|}
\hline Patient & Gender & $\begin{array}{c}\text { Age } \\
\text { (years) }\end{array}$ & $\begin{array}{l}\text { Tumour } \\
\text { site }\end{array}$ & Histology & TNM $^{b}$ & HPV & $\begin{array}{c}\text { Cumulative } \\
\text { dose (Gy) }\end{array}$ & $\begin{array}{c}\text { Concomitant } \\
\text { therapy }\end{array}$ & $\begin{array}{c}\text { Acute } \\
\text { toxicity }\end{array}$ & $\begin{array}{c}\text { Progress/ } \\
\text { death } \\
\text { (event }=1 \text { ) }\end{array}$ & $\begin{array}{c}\text { Locoregional } \\
\text { control }^{\mathrm{d}} / \text { overall } \\
\text { survival }^{\mathrm{e}} \text { (weeks) }\end{array}$ \\
\hline 1 & M & 58 & Oropharynx & SCC & $\begin{array}{l}\text { T3 } \\
\text { N2c } \\
\text { Mx }\end{array}$ & - & 70 & Cisplatin & Mild & $0 / 0$ & $13.3 / 20.9$ \\
\hline 2 & M & 66 & Larynx & SCC & $\begin{array}{l}\text { T2 No } \\
\text { MO }\end{array}$ & + & 70 & MMC & Mild & $0 / 0$ & $46.1 / 55.4$ \\
\hline 3 & M & 77 & Oropharynx & SCC & $\begin{array}{l}\text { T4 } \\
\text { N2a } \\
\text { M0 }\end{array}$ & + & 70 & MMC & Severe & $0 / 0$ & $47.0 / 55.1$ \\
\hline 4 & M & 75 & Hypopharynx & $\mathrm{SCC}$ & $\begin{array}{l}\mathrm{T} 4 \\
\mathrm{~N} 2 \mathrm{c} \\
\mathrm{M} 0\end{array}$ & - & 70 & None & Mild & $0 / 1$ & $23.1 / 26.9$ \\
\hline 5 & $\mathrm{~F}$ & 69 & Oropharynx & SCC & $\begin{array}{l}\text { T3 } \\
\text { N2c } \\
\text { M0 }\end{array}$ & NA & 70 & 5-FU/MMC & Mild & $0 / 0$ & $19.0 / 24.6$ \\
\hline 6 & M & 55 & Hypopharynx & $\mathrm{SCC}$ & $\begin{array}{l}\text { T4a } \\
\text { N2b } \\
\text { M0 }\end{array}$ & NA & 70 & Cisplatin & Mild & $1 / 0$ & $32.4 / 36.3$ \\
\hline 7 & M & 79 & Oropharynx & SCC & $\begin{array}{l}\mathrm{T} 2 \mathrm{c} \\
\mathrm{N} 2 \mathrm{c} \\
\mathrm{Mx}\end{array}$ & NA & 70 & None & Mild & $1 / 0$ & $31.3 / 36.3$ \\
\hline 8 & M & 55 & Larynx & $\mathrm{SCC}$ & $\begin{array}{l}\text { T3 NO } \\
\text { MO }\end{array}$ & NA & 70 & Cisplatin & Mild & $0 / 0$ & $13.6 / 20.1$ \\
\hline 9 & M & 75 & Oropharynx & SCC & $\begin{array}{l}\text { T3 N2 } \\
M x\end{array}$ & NA & 70 & None & Mild & $0 / 0$ & $19.0 / 25.3$ \\
\hline 10 & $\mathrm{~F}$ & 65 & Oropharynx & SCC & $\begin{array}{l}\mathrm{T} 4 \\
\mathrm{~N} 2 \mathrm{~b} \\
\mathrm{Mx}\end{array}$ & NA & 70 & Cisplatin & Mild & $1 / 0$ & $30.3 / 33.1$ \\
\hline 11 & $\mathrm{M}$ & 65 & Oropharynx & SCC & $\begin{array}{l}\text { T2 NO } \\
\text { MO }\end{array}$ & NA & 70.4 & Cisplatin & Mild & $0 / 0$ & $49.1 / 55.1$ \\
\hline \multicolumn{12}{|c|}{ 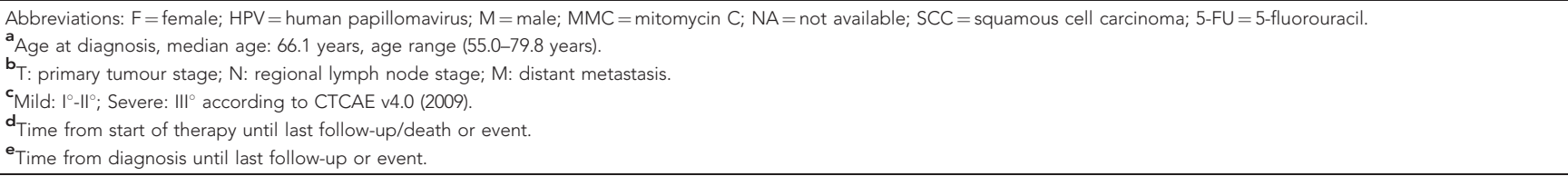 } \\
\hline
\end{tabular}

and high expression levels, respectively. Expression levels prior to therapy or after therapy were tested for correlation with LRC, PFS and OS. $P$-values were generated by log-rank testing.

Statistical analysis. The Mann-Whitney $U$-test was used to compare the plasma miRNA profiles of head and neck cancer patients before radiotherapy and healthy donors. To identify differential miRNA levels in plasma samples of patients prior to radiotherapy and after the second fraction of therapeutic irradiation the Wilcoxon test was performed. Unsupervised hierarchical clustering was performed using the top distinctive miRNAs applying the parameters maximum distance and Ward's method. $P$-values $<0.05$ were considered statistically significant. All statistical analyses were performed using the $\mathrm{R}$ Project for Statistical Computing, 2014.

\section{RESULTS}

Plasma miRNAs differentiate between healthy individuals and HNSCC patients. To test the hypothesis of tumour-related miRNA profiles in the plasma of HNSCC patients (discovery cohort), miRNA profiles prior to treatment were compared with miRNA profiles of healthy donors. The median number of detectable miRNAs in patients' plasma was 42.5 , whereas the median number of detectable miRNAs in plasma samples of healthy donors was 33.0, which demonstrated a significantly $(P=0.017)$ elevated number of plasma miRNAs in HNSCC patients compared with healthy subjects. About 56 plasma miRNAs displayed differential expression levels between healthy donors and patients (Supplementary Table 1). The majority of miRNAs revealed lower expression levels in the healthy controls, only four miRNAs showed higher expression compared with patients. Unsupervised hierarchical clustering based on the expression levels of the top 8 differentially expressed miRNAs (miR-21-5p, miR-28-3p, miR-142-3p, miR-186-5p, $m i R-191-5 p, m i R-197-3 p, m i R-425-5 p$ and $m i R-590-5 p)$ resulted in two main clusters (Supplementary Figure 1). Cluster 1 included 7 healthy donors and 1 patient, while cluster 2 represented 17 patients and 5 healthy donors, which demonstrated a significant $(P=0.003)$ differentiation of patient and healthy donor samples.

Technical validation of the array data for healthy donors and HNSCC patients prior to therapy was done with single qRT-PCR assays for selected miRNAs. Due to limited plasma samples, 3 out of 18 patients from the discovery cohort had to be excluded for technical validation. For validation of the patient-specific miRNAs, 11 out of the top 12 distinctive miRNAs were selected. The normalised $\mathrm{Ct}$ values resulting from single qRT-PCR assays demonstrated high consensus with the normalised $\mathrm{Ct}$ values resulting from the TaqMan array profilling for all of the 11 miRNAs (Supplementary Table 2). 
Plasma miRNAs that were detectable in $\leqslant 1$ healthy donor were tested for their ability to identify HNSCC patients (Table 3). MiR186-5p demonstrated the highest sensitivity and specificity.

Validation of therapy-responsive and patient-specific plasma miRNAs in an independent cohort of HNSCC patients. For an independent validation of the patient-specific and therapyresponsive miRNAs identified in the discovery cohort, expression levels in the plasma of a validation cohort comprising 11 HNSCC patients were determined before therapy and after two fractions of radiotherapy. Each of the 9 candidate therapy-responsive miRNAs that were previously identified in the discovery cohort (Summerer et al, 2013) showed a deregulation in at least 7 out of the 11 patients in the validation cohort after 2 days of radiotherapy (Supplementary Table 3). Similarly, all of the 10 patient-specific candidate miRNAs identified in the discovery cohort in the present study displayed significantly higher expression levels in the patients of the validation cohort compared with the healthy donors (Supplementary Table 4). MiR-590-5p was not included in the analysis of the patient-specific miRNAs since it was detectable only in $30 \%$ of the patients in the discovery cohort.

Expression of plasma miRNAs in tumour tissue of HNSCC patients. To further clarify the origin of the miRNAs in the circulation, we investigated the expression of therapy-responsive and patient-specific plasma miRNAs in tumour biopsies from the same patients. Formalin-fixed paraffin-embedded-tumour biopsies of 10 patients from the discovery cohort and 4 patients from the validation cohort were enriched for tumour material via microdissection and analysed with single qRT-PCR assays for the patient-specific and therapy-responsive miRNAs. All candidate miRNAs identified in plasma were also detectable in each of the 14 available FFPE tumour samples. The expression levels in plasma did not show significant correlation with the expression levels in the corresponding tumour tissues (Supplementary Table 5).

Plasma miRNAs as prognostic markers. Plasma miRNAs that were identified previously as therapy-responsive candidates in HNSCC patients (Summerer et al, 2013) as well as tumour-specific miRNAs from the present study were tested for their ability to predict LRC, PFS and OS. We investigated if the expression level of a candidate miRNA prior to therapy or after the second day of treatment correlated with LRC, PFS or OS. We identified candidate miRNAs showing a significant correlation $(P<0.05)$ or a trend for correlation $(P<0.2)$ with LRC, PFS or OS in the discovery cohort (Table 4). High expression levels of $m i R-186-5 p, m i R-374 b-5 p$ and $m i R-574-3 p$ prior to treatment correlated with reduced PFS and/or OS, and high expression of $m i R-28-3 p, m i R-142-3 p, m i R-191-5 p$, $m i R-195-5 p, m i R-425-5 p$ and $m i R-574-3 p$ after treatment showed correlation with worse prognosis. These candidate miRNAs were tested for correlation with LRC, PFS and OS in the validation cohort (Table 5). High expression of $m i R-186-5 p$ and $m i R-374 b-5 p$ prior to treatment significantly correlated with reduced LRC. MiR195-5p and $m i R-574-3 p$ correlated with reduced LRC, when highly expressed after treatment. High expression of $m i R-142-3 p$ after

\begin{tabular}{|c|c|c|}
\hline miRNA & Sensitivity & Specificity \\
\hline miR-186-5p & 0.938 & 0.917 \\
\hline$m i R-374 b-5 p$ & 0.312 & 1.000 \\
\hline miR-28-3p & 0.625 & 1.000 \\
\hline miR-195-5p & 0.562 & 1.000 \\
\hline miR-590-5p & 0.312 & 1.000 \\
\hline
\end{tabular}

treatment was validated as a marker for reduced LRC and PFS. We also tested the HPV status as a predictor of LRC, which resulted in a trend $(P=0.118)$ towards better LRC for HPV-positive cases in the discovery cohort (data not shown). Moreover, we tested the therapy-responsive and tumour-specific miRNAs for correlation with the HPV status. None of the candidate miRNAs showed a trend or a significant correlation with the HPV status (data not shown).

\section{DISCUSSION}

In this study we aimed to establish blood plasma miRNAs as minimally invasive biomarkers from the peripheral blood for therapy monitoring and prognosis in HNSCC patients. Further, we intended to shed light on the origin of these miRNAs. The significantly elevated number of detectable miRNAs in the plasma of HNSCC patients compared with healthy individuals is in accordance with previous findings showing that circulating miRNAs are frequently upregulated in cancer (Lawrie et al, 2008; Heneghan et al, 2010; Tsujiura et al, 2010). In our study we found that not only the total number of detectable miRNAs is higher in patients' plasma compared with healthy individuals but also that the majority of miRNAs showed higher expression levels in patients compared with healthy donors. In the discovery cohort of HNSCC patients, a signature of $m i R-21-5 p, m i R-28-3 p, m i R-142-$ 3p, $m i R-191-5 p, m i R-186-5 p, m i R-197-3 p, m i R-425-5 p$ and $m i R-$ 590-5p was identified to differentiate between HNSCC patients and healthy individuals. The fact that $m i R-21-5 p, m i R-28-3 p, m i R-142-$ $3 p, m i R-191-5 p$ and $m i R-425-5 p$ also represented therapy-responsive miRNAs indicates that these miRNAs are indeed tumour

\begin{tabular}{|c|c|c|c|}
\hline miRNA & $\begin{array}{c}P \text {-value } \\
\text { LRC }\end{array}$ & $\begin{array}{c}P \text {-value } \\
\text { PFS }\end{array}$ & $\begin{array}{c}P \text {-value } \\
\text { OS }\end{array}$ \\
\hline miR-28-3p (after treatment) & 0.069 & 0.027 & 0.092 \\
\hline miR-142-3p (after treatment) & 0.129 & - & - \\
\hline miR-186-5p (prior to treatment) & - & 0.165 & - \\
\hline miR-191-5p (after treatment) & 0.129 & 0.002 & 0.004 \\
\hline miR-195-5p (after treatment) & - & 0.029 & 0.130 \\
\hline miR-374b-5p (prior to treatment) & - & 0.039 & 0.036 \\
\hline miR-425-5p (after treatment) & 0.129 & 0.002 & 0.004 \\
\hline miR-574-3p (prior to treatment) & - & 0.165 & - \\
\hline miR-574-3p (after treatment) & 0.069 & 0.027 & 0.092 \\
\hline
\end{tabular}

Table 5. Correlation of expression of plasma miRNAs with LRC, PFS and OS in 11 HNSCC patients (validation cohort)

\begin{tabular}{|l|c|c|c|}
\hline miRNA & $\begin{array}{c}\boldsymbol{P} \text {-value } \\
\text { LRC }\end{array}$ & $\begin{array}{c}\boldsymbol{P} \text {-value } \\
\text { PFS }\end{array}$ & $\begin{array}{c}\boldsymbol{P} \text {-value } \\
\text { OS }\end{array}$ \\
\hline miR-142-3p (after treatment) & 0.025 & 0.018 & - \\
\hline $\begin{array}{l}\text { miR-186-5p (prior to } \\
\text { treatment) }\end{array}$ & 0.025 & - & - \\
\hline miR-195-5p (after treatment) & 0.025 & - & - \\
\hline $\begin{array}{l}\text { miR-374b-5p (prior to } \\
\text { treatment) }\end{array}$ & 0.025 & - & - \\
\hline $\begin{array}{l}\text { miR-574-3p (after treatment) } \\
\text { Abbreviations: HNSCC=head and neck squamous cell carcinoma; LRC = locoregional } \\
\text { control; miRNA = microRNA; OS=overall survival; PFS=progression-free survival. }\end{array}$ \\
\hline
\end{tabular}


related. Moreover, $m i R-21-5 p$ is a well-known tumour marker (Xiao-Chun et al, 2013; Zhu and $\mathrm{Xu}, 2014$ ) and upregulated $m i R$ 28-3p was suggested as a marker for oesophageal carcinoma (Liu et al, 2013). MiR-142-3p was previously reported to serve as prognostic marker in oesophageal carcinoma (Lin et al, 2012) and to predict the response to radiochemotherapy in rectal cancer (Hotchi et al, 2013). Similarly, miR-191-5p was already described as an important biomarker in cancer (Nagpal and Kulshreshtha, 2014) and $m i R-425-5 p$ was shown to predict survival and diseasefree survival in skin cancer patients (Fleming et al, 2014). We were able to further support the hypothesis that the therapy-responsive plasma miRNAs are most likely tumour related by demonstrating expression of all candidate miRNAs in all available tumour tissues from our patient cohorts. The lack of significant correlation of expression levels in the tumour tissues with the expression levels of the corresponding plasma samples is not surprising. The various mechanisms of tumour miRNAs entering the blood stream, e.g. apoptotic tumour cells or active secretion (Selth et al, 2012), do not allow the conclusion that tumour tissues show the same expression levels as corresponding plasma samples. Furthermore, tumour biopsies as used in this study do not reflect the miRNA expression levels of the whole tumour. Normal tissue would be also necessary for a meaningful comparison.

The therapy-responsive and the tumour-specific miRNAs identified in the discovery cohort were confirmed in an independent patient cohort again suggesting their suitability as predictive markers.

MiR-186-5p represented the best candidate in the plasma to differentiate between healthy individuals and HNSCC patients. It also appeared to be a prognostic marker since the expression level showed a trend for correlation with reduced PFS in the discovery cohort and significantly correlated with LRC in the validation cohort. A prognostic potential of $m i R-186-5 p$ was previously reported for oesophageal and lung carcinoma (Cai et al, 2013; Zhao et al, 2013). Circulating $m i R-374 b-5 p$ represents another promising prognostic marker since it exhibited significant correlation with PFS and OS in the discovery cohort and with LRC in the validation set prior to treatment. This is supported by a study suggesting a prognostic potential of this miRNA in prostate cancer (He et al, 2013). The additional miRNA candidates miR-142-3p, miR-195-5p and $m i R-574-3 p$ from this study correlated with prognosis after 2 days of treatment indicating that they might be useful tools for therapy monitoring.

MiR-574-3p is known as a stress-responsive miRNA, which was shown previously to serve as a prognostic marker in the serum of glioblastoma patients (Manterola et al, 2014). Moreover, it is published that it modulates the therapy response in breast cancer patients (Ujihira et al, 2015), which makes it a promising candidate for therapy monitoring in HNSCC. Similarly, $m i R-195-5 p$ is a well-known marker in the circulation of cancer patients (Igglezou et al, 2014) and was previously identified as prognostic marker in oesophageal carcinoma (Sun et al, 2014). The correlation of the therapy-responsive $m i R-142-3 p$ with LRC suggests $m i R-142-3 p$ as a marker for therapy success. An oncogenic role for $m i R-142-3 p$ was shown in a previous study (Lv et al, 2012) supporting the potential use of this miRNA as a prognostic biomarker. The ability to predict the response to therapy might decrease treatment failure and avoid patients' exposure to the side effects of ineffective therapies. The applicability of all five miRNAs as prognostic markers is further supported by the fact that these miRNA markers represent obviously tumour-related miRNAs.

Circulating miRNAs are known to be deregulated in cancer and to predict early disease (Healy et al, 2012). Their good availability as well as their stability makes them useful biomarker candidates. In the present study, we discovered $m i R-142-3 p, m i R-186-5 p, m i R-$ $374 b-5 p$, miR-195-5p and $m i R-574-3 p$ as the most promising HPVindependent markers for prognosis in the plasma of HNSCC patients treated with combined radiochemotherapy. Studies including a higher number of patients are needed to further validate the prognostic value of these marker miRNAs. We further showed that the same miRNAs were significantly overexpressed in plasma of HNSCC patients compared to healthy individuals, which supports the hypothesis that they originate from the tumour. Our findings represent an important contribution towards a clinical use of plasma miRNAs for therapy monitoring and a potential use in personalised treatment strategies.

\section{ACKNOWLEDGEMENTS}

We thank Laura Dajka and Klaudia Winkler for their excellent technical assistance, as well as Maya Flieger for the collection of clinical data of the patients and the support for patient recruitment. We also thank Ulrike Pflugradt for the management of patient data and tumour FFPE samples.

\section{CONFLICT OF INTEREST}

The authors declare no conflict of interest.

\section{REFERENCES}

The R Project for Statistical Computing (2014). Available at www.r-project.org. Adelstein DJ, Li Y, Adams GL, Wagner Jr H, Kish JA, Ensley JF, Schuller DE, Forastiere AA (2003) An intergroup phase III comparison of standard radiation therapy and two schedules of concurrent chemoradiotherapy in patients with unresectable squamous cell head and neck cancer. J Clin Oncol 21: 92-98.

Argiris A, Karamouzis MV, Raben D, Ferris RL (2008) Head and neck cancer. Lancet 371: 1695-1709.

Bledsoe T, Noble A, Hunter G, Rybicki L, Hoschar A, Chute D, Saxton J, Greskovich J, Adelstein D, Koyfman S (2013) Oropharyngeal squamous cell carcinoma with known human papillomavirus status treated with definitive chemoradiotherapy: patterns of failure and toxicity outcomes. Radiat Oncol 8: 174.

Blot WJ, Mclaughlin JK, Winn DM, Austin DF, Greenberg RS, Preston-Martin S, Bernstein L, Schoenberg JB, Stemhagen A, Fraumeni Jr JF (1988) Smoking and drinking in relation to oral and pharyngeal cancer. Cancer Res 48: 3282-3287.

Cai J, Wu J, Zhang H, Fang L, Huang Y, Yang Y, Zhu X, Li R, Li M (2013) miR186 downregulation correlates with poor survival in lung adenocarcinoma, where it interferes with cell-cycle regulation. Cancer Res 73: 756-766.

D'souza G, Kreimer AR, Viscidi R, Pawlita M, Fakhry C, Koch WM, Westra WH, Gillison ML (2007) Case-control study of human papillomavirus and oropharyngeal cancer. N Engl J Med 356: 1944-1956.

Fleming NH, Zhong J, Da Silva IP, Vega-Saenz De Miera E, Brady B, Han SW, Hanniford D, Wang J, Shapiro RL, Hernando E, Osman I (2014) Serum-based miRNAs in the prediction and detection of recurrence in melanoma patients. Cancer 121(1): 51-59.

Gehrmann M, Specht HM, Bayer C, Brandstetter M, Chizzali B, Duma M, Breuninger S, Hube K, Lehnerer S, Van Phi V, Sage E, Schmid TE, Sedelmayr M, Schilling D, Sievert W, Stangl S, Multhoff G (2014) Hsp70-a biomarker for tumor detection and monitoring of outcome of radiation therapy in patients with squamous cell carcinoma of the head and neck. Radiat Oncol 9: 131.

He HC, Han ZD, Dai QS, Ling XH, Fu X, Lin ZY, Deng YH, Qin GQ, Cai C, Chen JH, Jiang FN, Liu X, Zhong WD (2013) Global analysis of the differentially expressed miRNAs of prostate cancer in Chinese patients. BMC Genomics 14: 757.

Healy NA, Heneghan HM, Miller N, Osborne CK, Schiff R, Kerin MJ (2012) Systemic mirnas as potential biomarkers for malignancy. Int J Cancer 131: 2215-2222.

Heneghan HM, Miller N, Lowery AJ, Sweeney KJ, Newell J, Kerin MJ (2010) Circulating microRNAs as novel minimally invasive biomarkers for breast cancer. Ann Surg 251: 499-505. 
Hoffmann TK (2012) Systemic therapy strategies for head-neck carcinomas: current status. GMS Curr Top Otorhinolaryngol Head Neck Surg 11: Doc03.

Hotchi M, Shimada M, Kurita N, Iwata T, Sato H, Morimoto S, Yoshikawa K, Higashijima J, Miyatani T (2013) microRNA expression is able to predict response to chemoradiotherapy in rectal cancer. Mol Clin Oncol 1: 137142.

Igglezou M, Vareli K, Georgiou GK, Sainis I, Briasoulis E (2014) Kinetics of circulating levels of miR-195, miR-155 and miR-21 in patients with breast cancer undergoing mastectomy. Anticancer Res 34: 7443-7447.

Lawrie CH, Gal S, Dunlop HM, Pushkaran B, Liggins AP, Pulford K, Banham AH, Pezzella F, Boultwood J, Wainscoat JS, Hatton CS, Harris AL (2008) Detection of elevated levels of tumour-associated microRNAs in serum of patients with diffuse large B-cell lymphoma. Br J Haematol 141: 672-675.

Li J, Huang H, Sun L, Yang M, Pan C, Chen W, Wu D, Lin Z, Zeng C, Yao Y, Zhang P, Song E (2009) MiR-21 indicates poor prognosis in tongue squamous cell carcinomas as an apoptosis inhibitor. Clin Cancer Res 15: 3998-4008.

Licitra L, Perrone F, Bossi P, Suardi S, Mariani L, Artusi R, Oggionni M, Rossini C, Cantù G, Squadrelli M, Quattrone P, Locati LD, Bergamini C, Olmi P, Pierotti MA, Pilotti S (2006) High-risk human papillomavirus affects prognosis in patients with surgically treated oropharyngeal squamous cell carcinoma. J Clin Oncol 24: 5630-5636.

Lin R-J, Xiao D-W, Liao L-D, Chen T, Xie Z-F, Huang W-Z, Wang W-S, Jiang T-F, Wu B-L, Li E-M, Xu L-Y (2012) MiR-142-3p as a potential prognostic biomarker for esophageal squamous cell carcinoma. J Surg Oncol 105: 175-182.

Liu SG, Qin XG, Zhao BS, Qi B, Yao WJ, Wang TY, Li HC, Wu XN (2013) Differential expression of miRNAs in esophageal cancer tissue. Oncol Lett 5: $1639-1642$.

Lv M, Zhang X, Jia H, Li D, Zhang B, Zhang H, Hong M, Jiang T, Jiang Q, Lu J, Huang X, Huang B (2012) An oncogenic role of miR-142-3p in human T-cell acute lymphoblastic leukemia (T-ALL) by targeting glucocorticoid receptor-alpha and cAMP/PKA pathways. Leukemia 26: 769-777.

Manterola L, Guruceaga E, Pérez-Larraya JG, González-Huarriz M, Jauregui P, Tejada S, Diez-Valle R, Segura V, Samprón N, Barrena C, Ruiz I, Agirre A, Ayuso Á, Rodríguez J, González Á, Xipell E, Matheu A, López De Munain A, Tuñón T, Zazpe I, García-Foncillas J, Paris S, Delattre JY, Alonso MM (2014) A small noncoding RNA signature found in exosomes of GBM patient serum as a diagnostic tool. Neuro Oncol 16: 520-527.

Mitchell PS, Parkin RK, Kroh EM, Fritz BR, Wyman SK, PogosovaAgadjanyan EL, Peterson A, Noteboom J, O'briant KC, Allen A, Lin DW, Urban N, Drescher CW, Knudsen BS, Stirewalt DL, Gentleman R, Vessella RL, Nelson PS, Martin DB, Tewari M (2008) Circulating microRNAs as stable blood-based markers for cancer detection. Proc Natl Acad Sci 105: 10513-10518.

Nagpal N, Kulshreshtha R (2014) miR-191: an emerging player in disease biology. Front Genet 5: 99.

Nohata N, Hanazawa T, Kikkawa N, Mutallip M, Sakurai D, Fujimura L, Kawakami K, Chiyomaru T, Yoshino H, Enokida H, Nakagawa M,
Okamoto Y, Seki N (2011) Tumor suppressive microRNA-375 regulates oncogene AEG-1/MTDH in head and neck squamous cell carcinoma (HNSCC). J Hum Genet 56: 595-601.

Selth LA, Tilley WD, Butler LM (2012) Circulating microRNAs: macro-utility as markers of prostate cancer? Endocr Relat Cancer 19: R99-R113.

Sethi S, Ali S, Philip P, Sarkar F (2013) Clinical advances in molecular biomarkers for cancer diagnosis and therapy. Int J Mol Sci 14: 1477114784.

Summerer I, Niyazi M, Unger K, Pitea A, Zangen V, Hess J, Atkinson M, Belka C, Moertl S, Zitzelsberger H (2013) Changes in circulating microRNAs after radiochemotherapy in head and neck cancer patients. Radiat Oncol 8: 296.

Sun N, Ye L, Chang T, Li X, Li X (2014) microRNA-195-Cdc42 axis acts as a prognostic factor of esophageal squamous cell carcinoma. Int J Clin Exp Pathol 7: 6871-6879.

Tsujiura M, Ichikawa D, Komatsu S, Shiozaki A, Takeshita H, Kosuga T, Konishi H, Morimura R, Deguchi K, Fujiwara H, Okamoto K, Otsuji E (2010) Circulating microRNAs in plasma of patients with gastric cancers. Br J Cancer 102: 1174-1179.

Tuyns AJ, Esteve J, Raymond L, Berrino F, Benhamou E, Blanchet F, Boffetta P, Crosignani P, Del Moral A, Lehmann W, Merletti F, Pequignot G, Riboli E, Sancho-Garnier H, Terracini B, Zubiri A, Zubiri L (1988) Cancer of the larynx/hypopharynx, tobacco and alcohol: IARC international case-control study in Turin and Varese (Italy), Zaragoza and Navarra (Spain), Geneva (Switzerland) and Calvados (France). Int $J$ Cancer 41: 483-491.

Ujihira T, Ikeda K, Suzuki T, Yamaga R, Sato W, Horie-Inoue K, Shigekawa T, Osaki A, Saeki T, Okamoto K, Takeda S, Inoue S (2015) MicroRNA-574$3 p$, identified by microRNA library-based functional screening, modulates tamoxifen response in breast cancer. Sci Rep 5: 7641.

Xiao-Chun W, Wei W, Zhu-Bo Z, Jing Z, Xiao-Gang T, Jian-Chao L (2013) Overexpression of miRNA-21 promotes radiation-resistance of non-small cell lung cancer. Radiat Oncol 8: 146.

Zhao BS, Liu SG, Wang TY, Ji YH, Qi B, Tao YP, Li HC, Wu XN (2013) Screening of microRNA in patients with esophageal cancer at same tumor node metastasis stage with different prognoses. Asian Pac J Cancer Prev 14: 139-143.

Zheng J, Xue H, Wang T, Jiang Y, Liu B, Li J, Liu Y, Wang W, Zhang B, Sun M (2011) miR-21 downregulates the tumor suppressor P12CDK2AP1 and stimulates cell proliferation and invasion. J Cell Biochem 112: 872-880.

Zhu W, Xu B (2014) MicroRNA-21 Identified as predictor of cancer outcome: a meta-analysis. PLoS One 9: e103373.

This work is published under the standard license to publish agreement. After 12 months the work will become freely available and the license terms will switch to a Creative Commons AttributionNonCommercial-Share Alike 4.0 Unported License

Supplementary Information accompanies this paper on British Journal of Cancer website (http://www.nature.com/bjc) 